\title{
O Setor Externo Brasileiro no Novo Regime Cambial
}

\section{The Brazilian External Sector in the New Exchange Rate Regime}

\author{
Flávia Verusca Buturi Monarin ${ }^{1}$
}

\begin{abstract}
Resumo
O trabalho tem por objetivo identificar qual o comportamento do setor externo brasileiro após a mudança de regime cambial em 1999, procurando verificar se essa medida provocou um ajustamento externo. Para isso fez-se primeiramente uma revisão de literatura buscando perceber qual a avaliação que os economistas faziam quanto ao comportamento do câmbio e seu reflexo na balança comercial durante os primeiros anos da implantação do Real, depois se analisou a evolução da balança comercial durante os anos 1994 a 2001, com ênfase nas diferentes categorias e sua importância para um suposto retorno ao crescimento. Por fim, examina-se a formação bruta de capital fixo, no intuito de perceber as ações dos empresários brasileiros. Como conclusão, acredita-se que o Brasil ainda não realizou um ajuste externo, ficando vulnerável às variações do câmbio e a uma retomada do crescimento.
\end{abstract}

Palavras-chave: Regime cambial. balança comercial, ajuste externo.

\begin{abstract}
The objective of this work is to identify the behavior of the Brazilian external sector after the change of the exchange rate regime in 1999, trying to verify if there was an external adjustment. First, a literature review was done in order to realize which was the evaluation that the economists had made about the behavior of the exchange rate and its reflection in the trade balance during the first years of the monetary system (Real - R \$). After that, the evolution of the trade balance was analyzed during the years of 1994 to 2001, with emphasis on the different categories and its importance for a supposed return to its growth. Finally, the gross formation of fixed capital is examined in order to notice the Brazilian managers' actions. As a conclusion, it is believed that Brazil has not accomplished an external adjustment yet, which makes it vulnerable to the variations of the exchange rate as well as to a recovery of its growth.
\end{abstract}

Key words: Exchange rate regime, trade balance, external adjustment.

\section{Introdução}

Este trabalho tem por objetivo identificar qual o comportamento do setor externo brasileiro após a mudança de regime cambial em 1999, procurando verificar se houve, de fato, um ajustamento externo. Por definição de ajuste externo, não adotaremos a simples eliminação do déficit em conta corrente do Balanço de Pagamentos, mas o alcance de uma situação tal que o país não precise se preocupar com suas contas externas caso retorne a uma trajetória de crescimento.

Para atingir o objetivo proposto, este trabalho tratará dos seguintes pontos: as características positivas e negativas do regime cambial anterior a 1999; o regime cambial adotado em 1999; e o comportamento da balança comercial diante desse

\footnotetext{
${ }^{1}$ Mestre em Teoria Econômica no Programa de Mestrado da UEM/PR e Profa. Do Depto de Economia da UEL. Fone: (43)99989578. E-mail: fmonarin@uel.br.
} 
novo cenário. A metodologia adotada no trabalho foi descritiva e os dados são secundários.

\section{O regime Cambial no período pós-Real}

A balança comercial brasileira passou de um superávit de aproximadamente quinze milhões de reais, em 1992, para um déficit de mais de três milhões de reais em 1995. Um dos motivos apontados pelos economistas para este desajuste foi a taxa cambial, que estava sob um regime fixo e que vinha sendo considerada sobrevalorizada.

Vários autores alertavam que a sobrevalorização ${ }^{2}$ levaria a uma forte perda de competitividade da indústria brasileira e a um problema sistêmico no balanço de pagamentos. "O atual regime de câmbio e monetário gera endogenamente um desequilíbrio crescente entre o volume de reservas e a massa de ativos financeiros domésticos" (COUTINHO, 1996, p.144), o que acarreta uma vulnerabilidade externa acentuada e dificulta o sucesso da estabilidade e do crescimento. $^{3}$

Segundo Pastore e Pinotti (1998), a única vantagem do câmbio fixo reside na característica da taxa cambial poder ser utilizada como âncora nominal. Porém, como desvantagens, pode-se enumerar: a incapacidade de evitar a importação pelos países que adotam o câmbio fixo, dos ciclos econômicos verificados em outros países; a vulnerabilidade dos países que utilizam a combinação câmbio fixo e mobilidade de capital internacional a ataques especulativos (combinação que ocorria no Brasil); e por fim, a tendência à apreciação cambial provocada pelos fluxos de capitais, o que provocou o crescimento dos preços domésticos em relação aos internacionais, e teve como conseqüência a perda de competitividade.

No período em que vigorou o regime de câmbio fixo, o Brasil enfrentou três crises financeiras externas: 1994/95 - México; 1997 - Sudeste Asiático; e 1998 - Rússia. Nas três, o governo reagiu à saída de capitais com o aumento da taxa de juros, sustentando assim o regime cambial. "Porém, na sequiência da crise russa os fluxos de capitais não mais reagiram à elevação dos juros domésticos. Ao chegar a este ponto as autoridades não tiveram outra alternativa a não ser abandonar o regime cambial e flutuar a taxa de câmbio" (PASTORE; PINOTTI, 1999, p.175).

Desde 1996, a taxa de câmbio vinha sofrendo flutuações controladas pelo Banco Central e as desvalorizações alcançavam 7 a $8 \%$ ao ano. $\mathrm{Na}$ mudança de Janeiro de 1.999, a taxa cambial passou a ser determinada pelo mercado financeiro; e a desvalorização da moeda doméstica alcançou $48 \%$ em 1999, e 9,3\% em 2000.

Segundo Castro (1998) a balança comercial era considerada uma variável estratégica para o retorno ao crescimento. A simples expansão da economia acarretava o agravamento do desajuste externo, de modo que era necessário encontrar uma variável que ajustasse esse desequilíbrio: a balança de comércio.

\section{Comportamento da Balança de Comércio}

A balança comercial, para Piccinini e Puga (2001), realmente refletiu os contextos doméstico e internacional. Após um bom desempenho em 1997, quando as exportações cresceram $11 \%$ e as importações aumentaram $15 \%$, o comércio exterior brasileiro apresentou uma forte retração em 1998 e 1999. Assim, em 1999, as exportações e importações estavam em patamares de $9 \%$ e $20 \%$, respectivamente, abaixo do apresentado em 1997.

Para isso, será analisada a balança comercial brasileira no período de 1994 a 2001 conforme tabela 1 .

\footnotetext{
${ }^{2}$ Paulo Batista Junior, em obra já citada, chamou de maxivalorização

${ }^{3}$ Coutinho chega a chamar o regime de âncora cambial de bloqueio ao desenvolvimento.
} 
O Setor Externo Brasileiro no Novo Regime Cambial

Tabela 1- Evolução da Balança Comercial - em US\$ Milhões FOB (1994 - 2001)

\begin{tabular}{|c|c|c|c|c|c|c|c|c|c|}
\hline Discriminação & 1994 & 1995 & 1996 & 1997 & 1998 & 1999 & 2000 & 2001 & $\begin{array}{l}\text { Var. (\%) } \\
2001 / 00 \\
\end{array}$ \\
\hline EXPORTAÇÃO & 43.545 & 46.506 & 47.747 & 52.994 & 51.140 & 48.011 & 55.086 & 58.223 & 5,7 \\
\hline Básicos & 11.058 & 10.969 & 11.900 & 14.474 & 12.977 & 11.828 & 12.561 & 15.342 & 22,1 \\
\hline Produtos Industrializados & 31.852 & 34.711 & 35.026 & 37.672 & 37.507 & 35.311 & 41.027 & 41.144 & 0,3 \\
\hline Semi- Manufaturados & 6.893 & 9.146 & 8.613 & 8.478 & 8.120 & 7.982 & 8.499 & 8.244 & $-3,0$ \\
\hline Manufaturados & 24.959 & 25.565 & 26.413 & 29.194 & 29.387 & 27.329 & 32.528 & 32.900 & 1,1 \\
\hline Operações Especiais & 635 & 826 & 821 & 848 & 656 & 872 & 1.498 & 1.737 & 16,0 \\
\hline IMPORTAÇÃO & 33.078 & 49.972 & 53.301 & 59.746 & 57.746 & 49.272 & $\mathbf{5 5 . 8 3 5}$ & 55.581 & $-0,5$ \\
\hline $\begin{array}{l}\text { Mat.-Primas e Bens } \\
\text { Intermediários }\end{array}$ & 13.634 & 22.509 & 24.560 & 26.014 & 26.813 & 24.042 & 28.495 & 27.396 & $-3,9$ \\
\hline Bens de Consumo & 5.314 & 10.916 & 9.768 & 11.232 & 10.728 & 7.418 & 7.381 & 7.107 & $-3,7$ \\
\hline Comb. E Lubrificantes & 4.342 & 5.219 & 6.220 & 5.824 & 4.107 & 4.257 & 6.357 & 6.277 & $-1,3$ \\
\hline Bens de Capital & 9.788 & 11.328 & 12.753 & 16.676 & 16.098 & 13.555 & 13.602 & 14.801 & 8,8 \\
\hline SALDO & 10.467 & -3.466 & -5.554 & -6.752 & -6.606 & -1.261 & -749 & 2.642 & - \\
\hline
\end{tabular}

Fonte:SECEX

Percebe-se que há uma redução significativa do déficit da balança comercial no ano de 1999. De aproximadamente 6 bilhões em 1998, o resultado comercial de 1999 foi cerca de 1,2 bilhões negativos. No entanto pode-se perceber também, como destacam Piccinini e Puga (2001), que as exportações e as importações já haviam apresentado uma redução no ano de 1998 em relação a 1997.

Na variação das exportações do ano de 1997 para o de 1999 verificou-se uma queda de 9,40\%, impulsionada principalmente pelos produtos básicos, que apresentaram uma redução de $18,28 \%$, vindo a seguir os produtos manufaturados, com queda de $6,38 \%$.

Porém, verifica-se que a responsável pela redução do déficit no saldo comercial não foram as exportações, mas sim as importações, que apresentaram uma redução de $17,53 \%$ entre os anos de 1997 e 1999. As principais categorias foram os bens de consumo, com uma redução de $33,95 \%$, seguidos pelos combustíveis e lubrificantes $(-26,90 \%)$ e os bens de capital $(-8,71 \%)$.
Em 2000, ocorreu uma importante recuperação na balança de comércio: as exportações apresentaram um crescimento de $14,74 \%$ enquanto as importações cresceram 13,32\%, índice inferior às exportações. Os principais responsáveis pela variação positiva nas exportações foram as operações especiais $(71,79 \%)$ e os produtos manufaturados $(19,02 \%)$, enquanto com relação às importações os responsáveis pelo crescimento foram os combustíveis e lubrificantes $(49,33 \%)$ e as matérias primas e bens intermediários (18,52\%). É importante perceber que os bens de consumo, que haviam sofrido uma redução de 1997 para 1999 de cerca de 34\%, não apresentam recuperação como as demais categorias, e sofreram uma redução $0,5 \%$. Esse fato indica que os bens de consumo importados possuem uma alta elasticidade preço da demanda.

O comportamento dos bens de capital também é interessante, pois após uma retração de $18,71 \%$ de 1997 para 1999, apresentou somente uma variação positiva de $0,35 \%$ entre 2000 e 1999 . No ano de 2001, esta categoria ainda não havia recuperado o montante importado em $1997^{4}$.

\footnotetext{
4 É interessante lembrar que os bens de capital são categorias necessárias para modernização e expansão tecnológica e física da produção.
} 
Segundo Piccinini e Puga (2001), o motivo do forte impacto de retração nas exportações dos produtos básicos em 1999 foi a redução substancial dos preços internacionais. "A queda na demanda mundial de importantes itens da pauta de exportação brasileira juntamente com a interrupção dos créditos para o comércio exterior adiou os efeitos da desvalorização cambial de 1999 para 2000" (PICCININI; PUGA, 2001, p.7).

Segundo a Secretaria de Comércio Exterior (SECEX), todos os produtos de exportação do Brasil sofreram redução nos seus preços. A principal redução ocorreu no produto básico (com a base 100 em 1996, em 2001 o índice de preço estava em 68), o que levou a uma queda geral no índice de preço das exportações, como pode ser visto no gráfico 01 . No gráfico 1, também se vê o comportamento do quantum e do índice de preços dos produtos importados pelo Brasil. Claramente se observa que os produtos brasileiros ainda apresentam deterioração dos termos de troca em relação aos produtos produzidos externamente ${ }^{5}$.

Segundo Coutinho (1997), este comportamento é o reflexo do que ele chama, do ponto de vista industrial, uma especialização regressiva, pois as decisões de investimento realizadas no período pósestabilização concentraram-se nos setores produtores de commodities e bens intermediários. Ressalte-se, ainda que, a expansão da capacidade instalada vinha sendo retardada (até 1997, ano da publicação); e as inversões estavam se concentrando nos setores de bens duráveis, principalmente aqueles protegidos por tarifas aduaneiras elevadas.

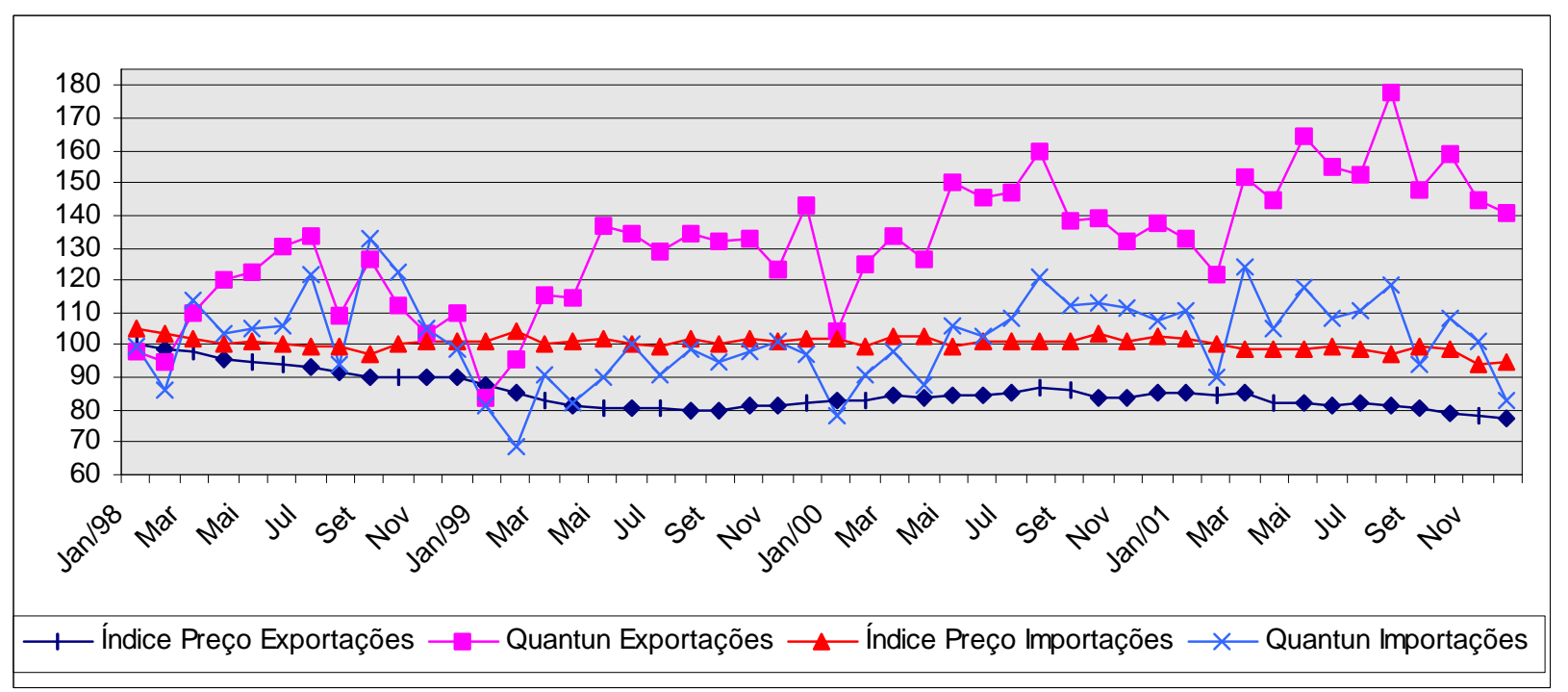

Fonte: SECEX

Gráfico 1- Índice de Preço e Quantum Total de Exportações e Importações (1998 - 2001)

Já Fonseca, Carvalho e Pourchet (2000) enfatizam que o setor industrial brasileiro deu ao mercado externo um enfoque marginal, fazendo com que o coeficiente de exportação permanecesse relativamente estável mesmo no período pósestabilização. Esse fato, segundo os autores, “aparenta que as exportações brasileiras de manufaturados ainda não foram significativamente afetadas pelo processo de modernização da indústria iniciado nos últimos anos" (FONSECA; CARVALHO; POURCHET, 2000, p.36)

\footnotetext{
${ }^{5}$ Por deterioração dos termos de troca, entende-se a perda de valor dos produtos exportados em relação aos importados.
} 
Para estes dois autores, o real motivo do baixo dinamismo das exportações brasileiras após a desvalorização cambial é o fato de as exportações brasileiras estarem excessivamente concentradas em bens intermediários, com pouco valor agregado, ou em produtos pouco dinâmicos no mercado internacional. No entanto, uma outra corrente, que inclui as autoridades econômicas, considera o baixo dinamismo resultado das deficiências sistêmicas estrutura tributária, infra-estrutura e as restrições financeiras domésticas constituintes do "Custo Brasil".

Iglesias (2001) possui ainda uma terceira visão com relação ao comportamento das exportações após a liberação cambial. Para ele, o comportamento exportador é intrinsecamente influenciado pelo comportamento da produção industrial e com base nisto o autor questiona: "o crescimento do setor exportador poderia ter sido maior nos últimos quinze anos, considerando o baixo crescimento da produção industrial, as flutuações cíclicas da produção, a baixa taxa de investimento e as diversas políticas macroeconômicas, que afetaram negativamente a atividade exportadora?" (IGLESIAS, 2001 p.5)

Com relação às deficiências sistêmicas, segundo a Secretaria de Comércio Exterior (2003), o governo brasileiro vem desenvolvendo várias atividades voltadas ao incentivo às exportações, como providências de ordem tributária; financiamento; simplificação e desburocratização; e de política industrial. Como exemplo, com relação à questão tributária foi retirada a cumulatividade do PIS/ COFINS; foi implementada isenção do Imposto de Renda sobre as remessas de capital para promoção de produtos brasileiros no exterior; e foi dada isenção de IPI para empresas com mais de $80 \%$ da receita total bruta voltada para o mercado externo. Com relação ao financiamento, foi primordialmente ampliada a atuação do BNDES como financiador das exportações (BNDES-exim) e a política industrial, está voltada principalmente para a agregação de valor, investimento em pesquisa e desenvolvimento (P\&D) e modernização tecnológica.
Apesar de todas as ações governamentais e da atuação favorável do novo regime cambial, o comportamento exportador não se alterou a ponto de auxiliar no processo de desenvolvimento. Ao invés disso, a participação das exportações brasileiras no total das exportações mundiais decresceu de $1,5 \%$ para $0,9 \%$. (BRESSER-PEREIRA; NAKANO, 2002)

Porém sabe-se que a expansão exportadora só virá com o aumento da competitividade das indústrias nacionais. Esta competitividade, além de pressupor aspectos favoráveis no câmbio, custo de capital reduzido (taxa de juros baixa) e infra-estrutura adequada, depende também de certas características da estrutura empresarial, capacidade de inovação, estratégias agressivas de conquista de mercado, investimento em pesquisa e desenvolvimento além de altas taxas de investimento em capital fixo e modernização tecnológica.

Para isso, serão analisadas as taxas de formação bruta de capital fixo no Brasil dos anos 1996 a 2001.

Tabela 2 - Formação Bruta de Capital Fixo - Máquinas e Equipamentos por Origem Nacional e Importado e Participação no PIB.

\begin{tabular}{|c|c|c|c|}
\hline \multirow{2}{*}{ Ano } & \multicolumn{2}{|c|}{ Preços correntes (R\$ 1000000$)$} & \multirow{2}{*}{$\begin{array}{c}\mathrm{FBCF} / \mathrm{PIB} \\
(\%)\end{array}$} \\
\hline & $\begin{array}{c}\text { PIB } \\
\text { R\$ Milhões }\end{array}$ & $\begin{array}{c}\text { FBCF Nacional } \\
\text { R\$ Milhões }\end{array}$ & \\
\hline 1996 & 778887 & 150050 & 19,26 \\
\hline 1997 & 870743 & 172939 & 19,86 \\
\hline 1998 & 914188 & 179982 & 19,69 \\
\hline 1999 & 973846 & 184098 & 18,12 \\
\hline 2000 & 1101255 & 212384 & 19,29 \\
\hline 2001 & 1200060 & 233376 & 19,45 \\
\hline
\end{tabular}

Fonte: Instituto Brasileiro de Geografia e Estatística. Departamento de Contas Nacionais (2003).

Como se pode perceber pela tabela 2, as taxas de formação bruta de capital sofreram pouca alteração ${ }^{6}$ para um período no qual havia uma alta

\footnotetext{
${ }^{6}$ Muitos economistas cogitam que a taxa ideal de FBCF no Brasil seria de $25 \%$ do PIB.
} 
concorrência externa decorrente da abertura comercial e da taxa cambial valorizada (até 1999)7. Esse período foi considerado de forte modernização industrial pelos representantes do governo.

Verifica-se, então, que as mudanças ocorridas neste período (1994-2001), tais como o aumento da produtividade $^{8}$, advieram principalmente da redução da quantidade empregada de pessoas e do uso de técnicas organizacionais e gerenciais que reduzem custos de produção, e não de aumento de investimento em tecnologia, pesquisa ou compra de maquinários. Como coloca Castro (1997), a partir de certo ponto estes ganhos de produtividade passam a perder o ímpeto, afinal não há como reduzir custos infinitamente.

\section{Conclusão}

Nota-se, então, que as exportações brasileiras estão muito aquém de apresentar as características necessárias de competitividade internacional, indicando um eventual ajuste externo. Porém, como Iglesias (2002) questiona, é muito difícil ampliar investimento com os atuais níveis da taxa de juros no Brasil. A infra-estrutura e a estrutura tributária, que representam uma condição básica para competitividade internacional, também estão longe de serem consideradas ideais. No entanto, no que cabe ao empresariado, este também não tem desempenhado um papel de empresário inovador, buscando o desenvolvimento de $\mathrm{P} \& \mathrm{D}$, capacidade de inovação, criação, modernização etc.

Assim, conclui-se, que dadas às características da balança comercial brasile ira, taxas altas de crescimento econômico ainda afetarão negativamente a balança comercial. Esse fato levará, senão a um déficit, a uma redução do saldo positivo, que terá reflexos no balanço de pagamentos.

Chama-se a atenção então para a necessidade de se olhar atentamente para o setor exportador, buscando sua reestruturação. Não só para o meio das políticas de financiamento, mas principalmente aquelas relacionadas às deficiências sistêmicas: $o$ estabelecimento de uma taxa de juros compatível e uma infra-estrutura adequada, para que o produto brasileiro possa concorrer isonomicamente com os produtos estrangeiros, bem como o incentivo à competição para que o empresariado conjuntamente realize sua parte como empreendedor.

\section{Referências}

BATISTA-JR, P. N. O Plano Real à luz da experiência mexicana e Argentina. Estudos Avançados, São Paulo, v.10, n.28, p.129-197, set./dez. 1996.

BRESSER-PEREIRA, L. C.; NAKANO, Yoshiaki. Uma estratégia de desenvolvimento com estabilidade. Revista de Economia Política, São Paulo, v.22, n.3, p.147-177, 2002.

CASTRO, A B. O Plano Real e o reposicionamento das empresas. In: VELLOSO, J. P. R. (Org). Brasil: desafios de um país em transformação. Rio de janeiro: J. Olympio, 1997. Publicação do IX Forum Nacional de Altos Estudos.

CASTRO, Crescimento reprimido versus balança de comércio como variável de ajuste. In: VELLOSO, J.P.R. (Org.). O Brasil e o mundo no limiar do novo século. Rio de janeiro: J. Olympio, 1998. v.2. Publicação do X Forum Nacional de Altos Estudos.

COUTINHO, L. A especialização regressiva: um balanço do desempenho industrial pós-estabilização. In: VELLOSO, J.P.R. (Org.). Brasil: desafios de um país em transformação. Rio de janeiro: J. Olympio, 1997. Publicação do IX Forum Nacional de Altos Estudos.

FONSECA, R.; CARVALHO-JR, M.C.; POURCHET, H. A orientação externa da indústria de transformação brasileira após a liberalização comercial. Revista de Economia Política, São Paulo, v.20, n.3, p. 22-38, jul./set. 2000.

INSTITUTO BRASILEIRO DE GEOGRAFIA E ESTATÍSTICA. Departamento de Contas Nacionais. Formação Bruta de Capital Fixo. Disponível em: <www.ibge.gov.br>. Acesso em: set. 2003.

\footnotetext{
${ }^{7}$ Mesmo para os anos de 1994 e 1995 as taxas não são muito diferentes das do final da década de 90. Estes dados podem ser encontrados na SECEX, mas como a metodologia é outra (lá só estão contabilizados os investimentos em máquinas e equipamentos), não é conveniente colocá-los aqui.

${ }^{8}$ Para um melhor detalhamento do aumento da produtividade da economia brasileira neste período vide Moreira (1999) e Coutinho (1997).
} 
IGLESIAS, R. Baixo dinamismo das exportações de produtos industrializados ou baixo crescimento da produção industrial Revista Brasileira de Comércio Exterior, Rio de Janeiro, v.13, n.67, p. 4-21, abr./jun. 2001.

MOREIRA, M. M. A indústria brasileira nos anos 90: o que já se pode dizer. In GIAMBIAGI, F.; MOREIRA, M. M. (Orgs). A Economia Brasileira nos anos 90. Rio de Janeiro: BNDES, 1999.

PASTORE, AF.; PINOTTI, M.C. Política econômica, vulnerabilidade externa e crescimento. In: VELLOSO, J.P.R. (Org). O Brasil e o mundo no limiar do novo século. Rio de Janeiro: J. Olympio, 1998. v.2. Publicação do X Forum Nacional de Altos Estudos.
PASTORE, AF; PINOTTI, M.C. Câmbio flutuante, inflação e crescim ento econôm ico. In:VELLOSO, JPR . ( rg) . A crise mundial e a nova agenda de crescimento. Rio de Janeiro: J. Olympio, 1999. Publicação do XI Forum Nacional de Altos Estudos.

PICCININI, M. S., PUGA, F. P. A balança comercial brasileira: desempenho 1997/2000. Rio de Janeiro: IPEA, 2001. (Texto para discussão ${ }^{\circ}$ 90).

SECRETARIA DE COMÉRCIO EXTERIOR. Anuário Estatístico. Disponível em: <www.mdic.gov.br>. Acesso em: set. 2003. 